\title{
THE RESULTS OF EARLY AND DELAYED TREATMENT OF INJURIES OF THE EXTENSOR TENDONS OF THE FINGERS IN OWN MATERIAL
}

\author{
Anna Deskur, $1, A, B, C, D, E$ Zbigniew Deskur $2, A, B, D, E$ \\ 1 Pomeranian Medical University \\ ${ }^{2}$ Faculty of Physical Culture and Health Promotion, University of Szczecin

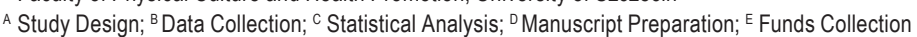

\author{
Address for corpespondence: \\ Zbigniew Deskur \\ University of Szczecin, Faculty of Physical Education and Health Promotion \\ Al. Piast 40b building 6, 71-065 Szczecin, Poland \\ E-mail: zdeskur@onet.pl
}

\begin{abstract}
Ahstract. The aim of this study was to evaluate the results of early and delayed surgical treatment and the rehabilitation of patients with traumatic injury in zone I of the extensor tendon of the fingers II-V. 47 patients after traumatic, closed damage of the extensor tendons of the fingers II-V of the hand were treated and examined. 17 women (36.2\%) and 30 men (63.8\%) aged 14-80 years were included in the study. Patients with a delayed first degree damage of the extensors tendon, as well as fourth degree damage, according to the Doleyle scale qualified for surgical treatment. Surgical treatment consisted of suturing the tendon band or restoring its attachment to the phalanx bone, as well as the arthrodesis of the distal interphalangeal (DIP) joint with Kirschner wire in extension. The wire was removed after 6 weeks. Rehabilitation treatment was carried out in order to restore a full range of motion of the fingers. Patients were under constant supervision of the medical team. The examination of the patients took place before and 3 months after the surgery. The presence of the pain was assessed by means of a 10-point VAS scale (Visual Analog Scale). A goniometer was used to measure the range of motion of patient's fingers. Crawford's scale was used to assess the results of treatment of injuries to the extensor tendons of the fingers. The early stages of treatment to these yielded excellent results in $84.2 \%$ of patients, $14.3 \%$ good results, $17.8 \%$ of satisfactory results and $3.6 \%$ of patients had poor results. The differences in the results were not statistically significant. Further operative intervention should be considered for patients with extensive damage to the tendon of the extensor finger with a greater detachment of a fragment of phalanx bone shortly after the injury. In patients with extensive damage to the tendon of the extensor finger with greater detachment of bone fragment of phalanx further surgery in the early period after injury should be considered.
\end{abstract}

Key WOrlls: damage to the extensor digitorum tendon, early and delayed treatment

\section{Introduction}

The most common damage to the tendon is closed tearing of the tendon band extensor in zone I. It is often associated with the dislocation of the bone from the dorsal portion of a distal phalanx. The abolition of activity sidebands and oblique extensor retinaculum leads to finger setting called "mallet, baseball or drop finger". No active 
extension phalanx further and continuing pain leads to a reduction in efficiency of hand (Doyle, 1999; Wańczyk, Pieniążek, Pelczar-Pieniążek, 2008).

Traumatic injury of the extensor tendons most commonly happens by hitting a hard object with the finger while practicing recreational activities or sports, during a fall, and while performing normal activities in daily life or work. Extensor tendon damage in sport often appears during team handball games (Cheung, Fung, Ip, 2012; Doyle, 1999; Mc Murtry, Isaacs; 2015; Wańczyk et al., 2008). Usually the patients undergo conservative treatment.

Surgical treatment according to most authors should be initiated in patients with a delayed diagnosis of injury of the extensor tendons of the fingers or substantial damage to the tendon from the bone fragment detachment without the possibility of bringing together fragments or subluxation phalanx (Gurnani, Hogendoorn, Rhemrev, 2014; Smit, Beets, Zeebregts, Rood, Welters, 2010). The surgical treatment of extensor tendon damage consists of stapling finger tendons, restoring its attachment and determining further interphalangeal joint in light hyperextension. If no improvement is observed, DIP arthrodesis in functional position it is sometimes necessary (Smit et al., 2010). Delay in treatment of the recent injury should not exceed two weeks (Altan, Alps, Baser, Yalcin, 2014). Surgical treatment shortens the treatment time by means of the earlier DIP joint immobilization which leads to earlier restoration of hand efficiency (Wańczyk et al., 2008).

The correct rehabilitation can help in obtaining good results. Active resistance exercises or redressing tractions are also used. The Oppenheimer dynamic rail plays a significant role in enhancing the treatment. Patients should have an established program of exercise and remain under the control of the therapists (Wańczyk et al., 2008).

The aim of this study was to evaluate the results of early and delayed surgical treatment and rehabilitation of patients with damage in zone I of the extensor tendon in fingers II to $\mathrm{V}$.

\section{Material and methods}

In the years from 2008 to 2011,47 patients were treated surgically for closed damage in zone I extensor tendon injury II to V finger There were $17(36.2 \%)$ and 30 men (63.8\%) aged between 14 and 80 years. The treatment and examination were carried out in SP Hospital at the Nowogard by the authors. Patients were treated surgically in the early period of up to 2 weeks (group I) and the delayed period (group II) 2 weeks after the extensor digitorum tendon damage.

Patients with a delayed treatment for closed digitorum tendon damage or avulsion fracture of a small piece of bone, as well as all those with further damage or attachment of the tendon to the bone with abnormal bone splinter group setting were qualified for surgery. They were patients with I and IV degree damage on the scale shown by Doyle (Doyle, 1999; Orhun, Dursun, Orhun E., Gurkan, Altun, 2009; Wańczyk et al. 2008). The diagnoses were confirmed by X-ray.

Surgical treatment consisted of suturing the tendon band or restoring its attachment to the phalanx bone, as well as the arthrodesis of the distal interphalangeal (DIP) joint with Kirschner wire of a thickness of 1-1.2 mm in light extension. The wire was removed after 6 weeks.

Rehabilitation treatment was carried out in order to restore a full range of movement of the fingers. Sometimes the dynamic rail was used. Patients were given an exercise program to do at home and they were under the constant supervision of the medical team.

Randomized patients were examined before treatment and at 3 months after surgery. The presence of pain was assessed by a 10-point VAS (Visual Analog Scale). The finger range of movement was measured 
using a goniometer and compared with the mobility of the appropriate finger of the healthy hand. The results of the treatment of extensor digitorum tendon damage were marked according to Crawford's skale (Doyle, 1999). The result was determined as follows: exellent - full extension, full flexion, no pain; good - 0-10 degrees extension loss, full flexion, no pain; fair - 10-25 degrees extension loss, insignificant flexion loss, no pain and poor - >25 degrees, small extension loss and persistent pain.

Evaluation of the results was made using Statistica's 10.0 Stat Soft. All tests were analyzed at a significance level of $p=0.05$. Non-parametric statistics were used: chi-square test and the Mann-Whitney test.

\section{Results}

We studied 47 patients treated for extensor tendon traumatic injury of the fingers II-V in zone I. Most tendon affected males (63.8\%), and in general people aged 31 to 50 years (Table 1 ).

Table 1. Number of patients treated for traumatic injury of the extensor tendons of the fingers divided according to sex and age

\begin{tabular}{|c|c|c|c|c|c|c|}
\hline \multirow{3}{*}{$\begin{array}{l}\text { The age } \\
\text { of patients }\end{array}$} & \multicolumn{4}{|c|}{ The number of patients treated with extensor tendon injury } & \multirow{2}{*}{\multicolumn{2}{|c|}{ Together }} \\
\hline & \multicolumn{2}{|c|}{ women } & \multicolumn{2}{|c|}{ men } & & \\
\hline & $\mathrm{n}$ & $\%$ & $\mathrm{n}$ & $\%$ & $\mathrm{n}$ & $\%$ \\
\hline $14-30$ & 1 & 2.1 & 8 & 17.0 & 9 & 19.1 \\
\hline $31-50$ & 10 & 21.3 & 13 & 27.6 & 23 & 48.9 \\
\hline $51-80$ & 6 & 12.8 & 9 & 19.2 & 15 & 32.0 \\
\hline Together & 17 & 36.2 & 30 & 63.8 & 47 & 100.0 \\
\hline
\end{tabular}

Damage to the extensor digitorum tendons of the hands frequently concerned the right hand $(68.1 \%)$ rather than the left hand $(31.9 \%)$. The most common injury was a broken finger $\mathrm{V}(36.2 \%)$, followed by IV (31.9) and III (21.3). The majority (56\%) of the cases of extensor tendon damage occurred during sport or recreational activities.

The number of ratings obtained after the treatment of the damaged extensor tendons of patients of group I and II were compared. In group I the percentage of patients with good results was higher and the other ones lower than in group II, the differences were not statistically significant $(p=0.41836)$, (Table 2, Figure 1).

Tahle 2. Results of the treatment of traumatic injuries to the extensor digitorum tendons in patients in group I and II according to the Crowford's scale

\begin{tabular}{|c|c|c|c|c|c|c|}
\hline \multirow{4}{*}{ Results of treatment } & \multicolumn{6}{|c|}{ The number of damaged extensor digitorum tendons hands patients in group } \\
\hline & \multicolumn{4}{|c|}{ I and II } & \multirow{2}{*}{\multicolumn{2}{|c|}{ Together }} \\
\hline & \multicolumn{2}{|c|}{1} & \multicolumn{2}{|c|}{ II } & & \\
\hline & $\mathrm{n}$ & $\%$ & $\mathrm{n}$ & $\%$ & $\mathrm{n}$ & $\%$ \\
\hline Excellent & 16 & 84.2 & 18 & 64.3 & 34 & 72.3 \\
\hline Good & 2 & 10.5 & 4 & 14.3 & 6 & 12.8 \\
\hline Fair & 1 & 5.3 & 5 & 17.8 & 6 & 12.8 \\
\hline Poor & 0 & 0.0 & 1 & 3.6 & 1 & 2.1 \\
\hline Together & 19 & 100.0 & 28 & 100.0 & 47 & 100.0 \\
\hline
\end{tabular}




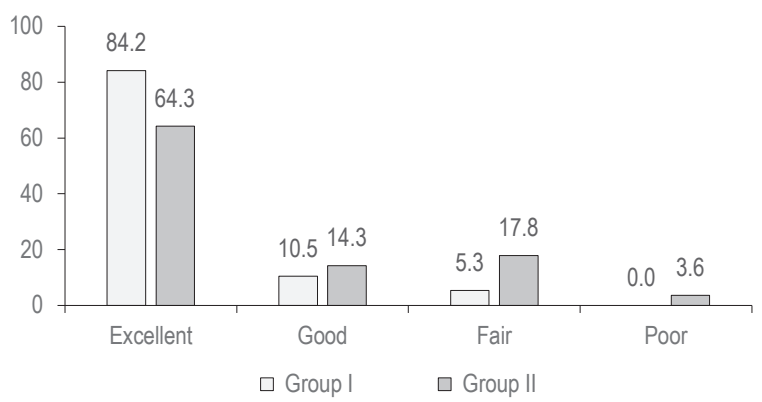

Figure 1. Results of treatment of traumatic injuries of the extensor digitorum tendons in patients in group I and II according to the Crawford's scale (\%)

The comparison of the average scores of group I and II indicates a slightly higher average score in Group I than II (Table 3). It can be assumed that a longer period of observation may allow for a greater difference in the results.

Tahle 3. Comparison of the average values of the damaged extensor tendons of fingers in patients in group I and II

\begin{tabular}{cccccccc}
\hline Grupa & $\mathrm{n}$ & $\mathrm{x}$ & $\mathrm{SD}$ & $\mathrm{v}$ & $\min$ & $\max$ & $\mathrm{p}$ \\
\hline I & 19 & 4.79 & 0.54 & 11.18 & 3 & 5 & 0.115865 \\
II & 28 & 4.39 & 0.92 & 20.86 & 2 & 5 & \\
\hline
\end{tabular}

\section{Discussion}

Traumatic injuries of the extensor tendons are most common in physically active people aged between 3150 years. These injuries often occur during sports or recreational activities. The damage usually occurs in the dominant hand and fingers V, IV and III (Doyle, 1999; Wańczyk et al., 2008).

Most of the closed damage in this region within the early period is treated conservatively. Respective rails, such as Zimmer, Stack or plaster casts are used for such immobilization. (Cheung et al., 2012; Doyle, 1999; Gurnani et al., 2014; Haagsma et al., 2014; Smit et al,. 2010; Wańczyk et al., 2008). Conservative treatment often fails due to a delay in diagnosis, incorrect immobilization or a lack of self-discipline in patient (Wańczyk et al., 2008). Furthermore, prolonged immobilization causes difficulties in maintaining proper hygiene, contributes to the formation of lesions in the form of pressure ulcers or necrosis at the site of the oppression rail. Treatment of neglected cases is difficult and requires a lot of experience (Doyle, 1999; Wańczyk et al., 2008).

Delays in conducting appropriate treatment on the damaged extensor tendon often results from the fact that either the patient or the treating team neglects this problem.

The early recognition of a significant degree of injury to the extensor tendon of the digitorum can be determined by the inability of an active extension of the distal phalanx. The loss of mobility of 10-20 degrees in an extensor distal phalanx indicates a partial failure and the total loss of a significant extension of the damaged tendon rupture DIP joint capsule or tendon detached from the bone attachment distal phalanx. Adherence to the recommended 
indications regarding surgical treatment of the corresponding damaged finger and hand with early treatment of the injury rather than late is likely to achieve better results. In order to restore optimal finger mobility rehabilitation treatment needs to be carried out by the therapeutic team. Inappropriate treatment can lead to permanent disability (Mc Murtry, Isaacs, 2015).

Recently, several authors have reported the results of surgical treatment of injuries to the extensor tendon in 15 to 34 people, scored the results according to the Crawford's scale and obtained excellent results of 53.3-79.4\%, good $11.8-40 \%$, fair $6.6 \%$ to $9 \%$ and poor 3\% (Jiang, Wang, Zhang, Zhao, Dang, 2015; Orhun et al., 2009; Wańczyk et al., 2008).

Many injuries were diagnosed and treated too late and not well enough. Treatment of neglected damage is difficult and will achieve worse results.

Altan et al. (2014) reported the results of conservative treatment assessed according to Crawford's scale in 28 patients treated in the period from 1 to 14 days after the injury, and have obtained $72 \%$ of excellent results and in 17 people treated in the period from 15 to 30 days obtained $59 \%$ excellent results. Early treatment rather than delayed led to better results.

Skillfully conducted rehabilitation treatment achieves positive results. Most authors state that a delayed or incorrectly diagnosed extensor tendon injury with extensive tendon damaged or with a large detached fragment of bone covering 30\% of the articular surface qualify for surgery (Doyle, 1999; Makhleufow, Deek, 2011; Smit et al., .2010; Wańczyk et al., 2008). The most common surgical treatment is to suture the strand tendon, the attachment to the distal phalanx and immobilization of the DIP joint using Kirschner wire (Doyle, 1999; Jabłecki, Kaczmarczyk, Domanasiewicz, 2009; Smit et al., 2010; Wańczyk et al., 2008). Surgical treatment compared with conservative treatment reduces the time, increases the range of movement of the finger, and improves the efficiency of a subjective assessment of the hand (Altan et al., 2014; Wańczyk et al., 2008).

\section{Conclusions}

1. Traumatic injury of the extensor tendons of the digitorum in the hand frequently occur in people who are physically active while doing fitness training and sports, during work or at home.

2. Most of the injuries of the extensor tendon of the digitorum can be treated conservatively, delay in the implementation of surgical treatment can result in many complications.

3. Greater damage to the tendon and the bone attachment, without the possibility of improving the fraction settings and cases neglected are an indication for surgery in the early period after injury of the extensor tendon of the digitorum.

4. Extensor tendon injury of the fingers qualified for surgical treatment in the early period after injury may allow for faster implementation of rehabilitation treatment and achievement of better outcomes.

\section{References}

Altan, E., Alps, N.B., Baser, R., Yalcin, L. (2014). Soft-tissue injuries mallet: A comparison of early and delayed treatment. J Hand Surg Am, 39 (10), 1982-1985.

Cheung, J.P., Fung, B., Ip, W.Y. (2012). Surgical treatment of chronic mallet finger. Hand Surg, 17 (3), 439-447.

Doyle, J.R. (1999.) Extensor tendons - acute injuries. In: D.P. Green, R.N. Hotchkiss, W.C. Pederson (eds.), Operative Hand Surgery. New York: Churchill Livingstone. 
Gurnani, N., Hogendoorn, J., Rhemrev, S. (2014). De malletvinger: opereren kontra spalken. Ned Tijdschr Geneeskd, 158, A 6941.

Haagsma, A., de Boer, H.L., Quintus, A.C., Strikkeling, N.J., Zeebregts, C.J., Smit, J.M. (2014). Treatment of mallet fingers in Dutch Hospitals: a nationwide survey of practice. Eur J Emerg Med, 3, 1.

Jabłecki, J., Kaczmarzyk, J., Domanasiewicz, A. (2009). Results of treatment of mallet finger to internal splinting - a preliminary report. Ortop Traumatol Rehabil, 11 (2), 138-144.

Jiang, B., Wang, P., Zhang, Y., Zhao, J., Dang, P. (2015). Results of treatment of mallet finger to internal splinting - a preliminary report. Medicine (Baltimore), 94 (6), E536.

Makhleufow, V.M., Deek, I.N. (2011). Surgical treatment of chronic mallet finger. Ann Plast Surg, 66 (6), 670-672.

Mc Murtry, J.T., Isaacs, J. (2015). Extensor tendons injuries. Clin Sports Med, 34 (1), 167-180.

Orhun, H., Dursun, M., Orhun, E., Gurkan, V., Altun, G. (2009). Open reduction and K-wire fixation of mallet finger injuries: mid-term results. Acta Orthop Traumatol Turc, 43 (5), 395-399.

Smit, J.M., Beets, M.R., Zeebregts, C.J., Rood, A., Welters, C.F. (2010). Treatment options for mallet finger: a review. Plast Reconstr Surg, 126 (5), 1624-1629.

Wańczyk, A., Pieniążek, M., Pelczar-Pieniążek, M. (2008). Metoda i wyniki rehabilitacji w uszkodzeniach ścięgien prostowników palców II-V w I i ll strefie urazowej. Ortop Traumatol Rehabil, 10 (3), 218-225.

Cite this article aS. Deskur, A., Deskur, Z. (2016). The Results of Early and Delayed Treatment of Injuries of the Extensor Tendons of the Fingers in Own Material. Central European Journal of Sport Sciences and Medicine, 13 (1), 117-122. DOI: 10.18276/cej.2016.1-12. 